\title{
Article \\ PECAM1, COL4A2, PHACTR1, and LMOD1 Gene Polymorphisms in Patients with Unstable Angina
}

\author{
Krzysztof Kosiński ${ }^{1}$, Damian Malinowski ${ }^{2}$, Krzysztof Safranow $^{3}\left(\mathbb{D}\right.$, Violetta Dziedziejko ${ }^{3}(\mathbb{D}$ \\ and Andrzej Pawlik 4,*iD
}

check for updates

Citation: Kosiński, K.; Malinowski, D.; Safranow, K.; Dziedziejko, V.; Pawlik, A. PECAM1, COL4A2, PHACTR1, and LMOD1 Gene Polymorphisms in Patients with Unstable Angina. J. Clin. Med. 2022 11,373. https://doi.org/10.3390/ jcm11020373

Academic Editor: Tommaso Gori

Received: 29 November 2021

Accepted: 11 January 2022

Published: 13 January 2022

Publisher's Note: MDPI stays neutral with regard to jurisdictional claims in published maps and institutional affiliations.

Copyright: (C) 2022 by the authors. Licensee MDPI, Basel, Switzerland. This article is an open access article distributed under the terms and conditions of the Creative Commons Attribution (CC BY) license (https:// creativecommons.org/licenses/by/ $4.0 /$ )
1 Department of Cardiology, Hospital in Szczecin, Arkonska 4, 71-455 Szczecin, Poland; kriskos70@gmail.com 2 Department of Experimental and Clinical Pharmacology, Pomeranian Medical University, 70-111 Szczecin, Poland; damian.malinowski@pum.edu.pl

3 Department of Biochemistry and Medical Chemistry, Pomeranian Medical University, 70-111 Szczecin, Poland; chrissaf@mp.pl (K.S.); viola@pum.edu.pl (V.D.)

4 Department of Physiology, Pomeranian Medical University in Szczecin, Powstańców Wlkp. 72, 70-111 Szczecin, Poland

* Correspondence: pawand@poczta.onet.pl

\begin{abstract}
Coronary artery disease (CAD) is a syndrome resulting from myocardial ischaemia of heterogeneous pathomechanism. Environmental and genetic factors contribute to its development. Atherosclerotic plaques that significantly narrow the lumen of coronary arteries cause symptoms of myocardial ischaemia. Acute coronary incidents are most often associated with plaque rupture or erosion accompanied by local activation of the coagulation system with thrombus formation. Plaque formation and stability are influenced by endothelial function and vascular smooth muscle cell function. In this study, we investigated the association between polymorphisms in genes affecting endothelial and vascular smooth muscle cell (VSMC) function and the occurrence of unstable angina pectoris. The aim of this study was to evaluate the association between the PECAM1 (rs1867624), COL4A2 (rs4773144), PHACTR1 (rs9349379) and LMOD1 (rs2820315) gene polymorphisms and the risk of unstable angina. The study included 232 patients with unstable angina diagnosed on the basis of clinical symptoms and coronary angiography and 144 healthy subjects with no significant coronary lumen stenosis at coronary angiography. There were no statistically significant differences in the distribution of COL4A2 rs4773144 and PECAM1 rs1867624 gene polymorphisms between patients with unstable angina and control subjects. In patients with unstable angina, there was an increased frequency of PHACTR1 rs9349379 G allele carriers (GG and AG genotypes) (GG+AG vs. AA, OR 1.71; 95\% CI $1.10-2.66, p=0.017$ ) and carriers of the LMOD1 rs2820315 T allele (TT and CT genotypes) (TT+CT vs. CC, OR $1.65 ; 95 \%$ CI 1.09-2.51, $p=0.019$ ) compared to the control group. The association between these alleles and unstable angina was confirmed by multivariate logistic regression analysis, in which the number of $\mathrm{G}$ (PHACTR1 rs9349379) and T (LMOD1 rs2820315) alleles was an independent risk factor for unstable angina. The results suggest an association between PHACTR1 rs9349379 and LMOD1 rs2820315 polymorphisms and the risk of unstable angina.
\end{abstract}

Keywords: coronary artery disease; unstable angina; polymorphism; genetic

\section{Introduction}

Coronary artery disease (CAD) is a syndrome resulting from myocardial ischaemia of heterogeneous pathomechanism. In most cases, it is caused by atherosclerosis of the coronary arteries. Environmental and genetic factors contribute to its development. Factors such as smoking, hyperlipidaemia and disorders of lipid and carbohydrate metabolism are so-called modifiable risk factors. Genetic factors are still poorly understood, but recent years have brought great progress in this area. In particular, it concerns the identification of so-called single nucleotide polymorphisms (SNPs), which may be associated with the risk 
of CAD. Currently, more than 60 polymorphisms have been identified that may increase the risk of developing CAD [1].

CAD is a reflection of the systemic atherosclerotic process, which is a specific type of inflammation taking place within the inner membrane of the arterial walls. Initial atherosclerotic lesions consist mainly of macrophages transforming into foam cells and few lymphocytes [2]. With favourable environmental and genetic conditions, these primary lesions transform into more advanced and irreversible atherosclerotic plaques. In the process of the formation of mature atherosclerotic lesions, the following phenomena occur: migration of smooth muscle cells from the vascular membrane with their phenotypic reprogramming and proliferation, accumulation of extracellular matrix proteins, neovasculogenesis, apoptosis, activation of the coagulation system and calcification [3].

The inflammatory response is initiated and sustained by various pathological factors, among which oxidized LDL cholesterol particles (oxLDL) and heat shock proteins (HSP) seem to play a leading role. In response to the damaging factor, monocytes transmigrate from circulating blood to the inner membrane and are transformed into macrophages and then lipid-accumulating foam cells [4]. Endothelial dysfunction, which can be an initiating factor, as well as vascular smooth muscle cells, play a significant role in monocyte recruitment and platelet activation. Under the influence of antigen-presenting cells and the cytokines (such as IL-1 and TNF- $\alpha$ ) and chemokines produced, the inflammatory process is further propagated through the involvement of specific immune mechanisms [5].

Atherosclerotic plaques that significantly narrow the lumen of coronary arteries cause symptoms of myocardial ischaemia. Acute coronary incidents are most often associated with plaque rupture or erosion accompanied by local activation of the coagulation system with thrombus formation [2]. They can critically restrict or completely prevent blood flow in the artery and consequently cause necrosis of a specific area of the myocardium. Atherosclerotic plaques prone to rupture, characterized by a large necrotic nucleus and a thin fibrous cap, are crucial in the etiopathogenesis of acute coronary syndromes [6]. Plaque formation and stability are influenced by endothelial function and vascular smooth muscle cell function. In this study, we investigated the association between polymorphisms in genes affecting endothelial and vascular smooth muscle cell (VSMC) function and the occurrence of unstable angina pectoris.

The phosphatase and actin regulator 1 (PHACTR1) gene is located on chromosomal locus 6p24. The rs9349379 polymorphism located within the intron of PHACTR1 gene has been shown to affect its expression in vascular tissue [7]. PHACTR1 regulates transcription factors responsible for extracellular signal transduction and activation of pathways that control differentiation, morphogenesis, proliferation, apoptosis of vascular endothelial cells and, consequently, atherogenesis and plaque stability [8-10]. The product of the PHACTR1 gene is a protein phosphatase 1 (PP1-protein phosphatase 1) and actin binding protein. PP1 influences endothelial function and production of NO [11]. Previous studies have shown an association between the PHACTR1 gene rs9349379 polymorphism and the severity of atherosclerotic lesions in the coronary arteries [12-16].

LMOD1 (leiomodin 1) belongs to the actin filament neucleator family and is found in smooth muscle cells, including vascular smooth muscle cells [17]. The gene encoding this protein is located at locus 1q32. The rs2820315 polymorphism was shown to affect LMOD1 gene expression in coronary artery smooth muscle cells [18]. LMOD1 appears to play a key role in maintaining the phenotype of differentiated vascular smooth muscle cells and sustaining their contractile function [19]. Vascular muscle cells that have undergone phenotypic transformation produce excess of extracellular matrix, undergo apoptosis, accumulate lipids, secrete growth factors and proinflammatory cytokines, and contribute to monocyte recruitment [20]. Decreased expression of this gene leads to increased proliferation and migration as well as loss of contractile elements in smooth muscle cells of the coronary arteries and to increased atherosclerosis and plaque instability. 
PECAM1 (CD31) encodes platelet-endothelial cell adhesion factor 1, a trans-membrane glycoprotein belonging to the immunoglobulin family found on the surface of platelets, monocytes and neutrophils [21]. The PECAM1 gene is located in the 17q23 region. PECAM1 molecules concentrate on the lateral surfaces of adjacent cell membranes in the endothelium. Mutual binding of PECAM1 molecules to each other through so-called transhomophilic connections leads to the formation of a specific protective barrier of the endothelium [22]. Down regulation of PECAM1 expression leads to a violation of the integrity of the endothelial barrier and an increase in its permeability, which consequently lead to the activation of inflammatory processes in the arterial inner membrane [23]. The protective function of PECAM1 is probably impaired at sites of active inflammation, i.e., in areas of arteries involved in the atherosclerotic process. The rs 1867624 polymorphism has been shown to affect the expression of the PECAM gene and thus the formation of atherosclerotic lesions in the vessels and the development of coronary artery disease [24].

The COL4A1/COL4A2 gene cluster, a member of the type IV collagen family, is located in region 13q34 and includes exons 52 and 48. This type of collagen is the main building block of the basement membrane, which connects the epithelial cell layer and vascular endothelium through integrins and other surface molecules [25]. SNP rs4773144 is located within intron 3 of the COL4A2 gene. This polymorphism affects COL4A2 gene expression and thus the development of atherosclerotic lesions [26]. Decreased COL4A2 gene expression results in altered vascular smooth muscle cell phenotype, compromised endothelial barrier integrity, and apoptosis of vascular smooth muscle and endothelial cells [27]. Thus, type IV collagen deficiency promotes atherogenesis by altering the properties of vascular smooth muscle cells. In turn, weakening of the endothelial basement membrane with reduced collagen IV content facilitates monocyte recruitment from the circulation by increasing VCAM-1 expression Previous studies suggested an association between these polymorphisms and ischemic heart disease, but the results are inconsistent.

The aim of this study was to evaluate the association between the PECAM1 (rs1867624), COL4A2 (rs4773144), PHACTR1 (rs9349379) and LMOD1 (rs2820315) gene polymorphisms and the risk of unstable angina.

\section{Material and Methods}

The study included 232 patients with unstable angina treated in the Department of Cardiology in years 2017-2018. The diagnosis of unstable angina was made on the basis of typical clinical presentation, including angina at rest associated with acute or transient ST segment or T wave changes in ECG without an increase in markers of myocardial injury (troponin $\mathrm{T}$, myoglobin) and confirmation of significant coronary artery lumen stenosis $(>70 \%)$ during coronary angiography. Patients with a final diagnosis of myocardial infarction based on a significant increase in markers of myocardial injury (troponin $\mathrm{T}$, myoglobin) were excluded from the study. Patients with autoimmune diseases and cancer were also excluded from the study.

The control group consisted of 144 healthy subjects without a history of inflammatory disease or cancer. In this group of patients, no significant coronary lumen stenosis was detected at coronary angiography, performed for the diagnosis of unexplained chest pain. Clinical characteristics of patients and controls are shown in Table 1. The study was approved by the ethics committee at Pomeranian Medical University, Szczecin, Poland (KB-0012/46/17) and written informed consent was obtained from all subjects. 
Table 1. Clinical characteristics of patients and control subjects.

\begin{tabular}{cccc}
\hline \multirow{2}{*}{ Parameters } & Control Group & Unstable Angina & \multirow{2}{*}{$\boldsymbol{p}^{*}$} \\
\cline { 2 - 3 } & Median (Q1-Q3) & Median (Q1-Q3) & $<0.0001$ \\
Age (ears) & $67(59-75)$ & $61(55-69)$ & $<0.0001$ \\
BMI $\left(\mathrm{kg} / \mathrm{m}^{2}\right)$ & $26(24-28)$ & $28(26-31)$ & $<0.0001$ \\
CH $(\mathrm{mg} / \mathrm{dL})$ & $186(167-213)$ & $227(187-267)$ & $<0.0001$ \\
HDL $(\mathrm{mg} / \mathrm{dL})$ & $54(49-57)$ & $43(38-50)$ & $<0.0001$ \\
LDL $(\mathrm{mg} / \mathrm{dL})$ & $112(87-138)$ & $162(127-190)$ & $<0.0001$ \\
TG $(\mathrm{mg} / \mathrm{dL})$ & $87(74-132)$ & $130(86-172)$ & $p^{\wedge}$ \\
\hline & $\mathrm{N}(\%)$ & $\mathrm{N}(\%)$ & $<0.0001$ \\
Sex $(\mathrm{male})$ & $54(37.5 \%)$ & $172(74.1 \%)$ & $<0.0001$ \\
Arterial hypertension & $57(39.6 \%)$ & $145(62.5 \%)$ & $<0001$ \\
\hline Diabetes mellitus & $9(6.3 \%)$ & $57(24.6 \%)$ & \\
\hline
\end{tabular}

* Mann-Whitney U test; ' Fisher exact test; Q1—lower quartile, Q3-upper quartile; BMI—body mass index, $\mathrm{CH}$ - total cholesterol in serum, HDL—high density cholesterol in serum, LDL-low density cholesterol in serum, TG-triacylglycerols in serum.

\subsection{Genotyping}

Genomic DNA was extracted from $1 \mathrm{~mL}$ of peripheral blood samples using a Genomic Mini AX Blood 1000 Spin kit (A\&A Biotechnology, Gdynia, Poland) following manufacturers protocol. DNA was subsequently standardized to equal concentrations of $20 \mathrm{ng} / \mu \mathrm{L}$, based on spectrophotometric absorbance measurement at 260/280 nm (DeNovix DS-11 FX+ Spectrophotometer/Fluorometer, Wilmington, DE, USA). Genotyping for the following single nucleotide polymorphisms (SNPs): PECAM1 rs1867624, COL4A2 rs4773144, PHACTR1 rs9349379 and LMOD1 rs2820315 was performed using a pre-validated allelic discrimination TaqMan real-time PCR assays (Life Technologies, Carlsbad, CA, USA) and TaqMan GTXpress Master Mix (Life Technologies, Carlsbad, CA, USA). Fluorescence data were captured using the ViiA7 Real-Time PCR System (Applied Biosystems, San Francisco, CA, USA) after 40 reaction cycles. Specific genotypes were assigned to individual samples after analysis with TaqMan Genotyper software (Thermo Fisher Scientific, Waltham, MA, USA).

\subsection{Statistical Analysis}

The concordance of genotype distributions with Hardy-Weinberg equilibrium (HWE) was assessed using Fisher's exact test. The chi-square test was used to compare the distributions of genotypes and alleles between groups. The distribution of quantitative clinical parameters in the study group differed significantly from the normal distribution (ShapiroWilk test), so they were compared between groups using the non-parametric Mann-Whitney test. Multivariate logistic regression analysis, including the number of $\mathrm{G}$ alleles of the PHACTR1 variant rs9349379 and the number of T alleles of the LMOD1 variant rs2820315, as well as seven variables (age, sex, BMI, smoking, diabetes mellitus, hypertension, serum HDL cholesterol) as independent variables and the presence of unstable angina as the dependent variable, was performed to evaluate whether the PHACTR1 rs9349379 and LMOD1 rs2820315 polymorphisms were independent predictors of unstable angina. $p<0.05$ was considered statistically significant.

The statistical power of study with 232 patients and 144 controls was sufficient to detect with $80 \%$ probability the real effect size of allele-phenotype association corresponding to odds ratio (OR) $<0.64$ or $>1.53$ for COL4A2 rs4773144, PECAM1 rs1867624, and PHACTR1 rs9349379, and OR $<0.59$ or $>1.59$ for LMOD1 rs2820315.

\section{Results}

The distributions of the studied polymorphisms are shown in Tables 2 and 3. There were no statistically significant differences in the distribution of COL4A2 rs4773144 and PECAM1 rs1867624 gene polymorphisms between patients with unstable angina and control subjects. 
In patients with unstable angina, there was an increased frequency of PHACTR1 rs9349379 G allele carriers (GG and AG genotypes) (GG+AG vs. AA, OR 1.71; 95\% CI 1.10-2.66, $p=0.017$ ) and carriers of the LMOD1 rs2820315 T allele (TT and CT genotypes) (TT+CT vs. CC, OR $1.65 ; 95 \%$ CI 1.09-2.51, $p=0.019$ ) compared to the control group (Table 3).

Table 2. Distribution of COL4A2 rs4773144 and PECAM1 rs1867624 genotypes and alleles in patients with unstable angina and controls.

\begin{tabular}{|c|c|c|c|c|c|c|c|c|}
\hline & \multicolumn{2}{|c|}{ Control Group } & \multicolumn{2}{|c|}{ Unstable Angina } & \multirow{2}{*}{$p$ Value } & \multirow{2}{*}{$\begin{array}{c}\text { Compared Genotypes } \\
\text { or Alleles }\end{array}$} & \multirow{2}{*}{$p$ Value } & \multirow{2}{*}{ OR $(95 \%$ CI) } \\
\hline & $\mathrm{n}$ & $\%$ & $\mathrm{n}$ & $\%$ & & & & \\
\hline \multicolumn{9}{|c|}{$\begin{array}{c}\text { COL4A2 rs } 4773144 \\
\text { genotype }\end{array}$} \\
\hline AA & 49 & $34.03 \%$ & 63 & $27.16 \%$ & \multirow{5}{*}{0.35} & GG+AG vs. AA & 0.16 & $1.38(0.88-2.17)$ \\
\hline $\mathrm{AG}$ & 72 & $50.00 \%$ & 125 & $53.88 \%$ & & GG vs. $A G+A A$ & 0.46 & $1.23(0.71-2.14)$ \\
\hline \multirow[t]{3}{*}{ GG } & 23 & $15.97 \%$ & 44 & $18.97 \%$ & & GG vs. AA & 0.21 & $1.49(0.79-2.79)$ \\
\hline & & & & & & AG vs. AA & 0.21 & $1.35(0.84-2.17)$ \\
\hline & & & & & & GG vs. AG & 0.74 & $1.10(0.62-1.97)$ \\
\hline \multicolumn{9}{|c|}{ Allele } \\
\hline A & 170 & $59.03 \%$ & 251 & $54.09 \%$ & & \multirow[b]{2}{*}{ G vs. A } & \multirow[b]{2}{*}{0.19} & \multirow{2}{*}{$1.22(0.91-1.65)$} \\
\hline G & 118 & $40.97 \%$ & 213 & $45.91 \%$ & & & & \\
\hline \multicolumn{9}{|c|}{$\begin{array}{c}\text { PECAM1 rs1867624 } \\
\text { genotype }\end{array}$} \\
\hline $\mathrm{TT}$ & 44 & $30.56 \%$ & 74 & $31.90 \%$ & \multirow{5}{*}{0.19} & CC+TC vs. TT & 0.79 & $0.94(0.60-1.47)$ \\
\hline $\mathrm{TC}$ & 60 & $41.67 \%$ & 112 & $48.28 \%$ & & CC vs. TC $+\mathrm{TT}$ & 0.074 & $0.64(0.40-1.05)$ \\
\hline \multirow[t]{3}{*}{$\mathrm{CC}$} & 40 & $27.78 \%$ & 46 & $19.83 \%$ & & CC vs. TT & 0.19 & $0.68(0.39-1.20)$ \\
\hline & & & & & & TC vs. TT & 0.67 & $1.11(0.68-1.81)$ \\
\hline & & & & & & CC vs. TC & 0.071 & $0.62(0.36-1.04)$ \\
\hline \multicolumn{9}{|c|}{ Allele } \\
\hline $\mathrm{T}$ & 148 & $51.39 \%$ & 260 & $56.03 \%$ & & \multirow{2}{*}{ C vs. T } & \multirow{2}{*}{0.21} & \multirow{2}{*}{$0.83(0.62-1.11)$} \\
\hline $\mathrm{C}$ & 140 & $48.61 \%$ & 204 & $43.97 \%$ & & & & \\
\hline
\end{tabular}

Table 3. Distribution of PHACTR1 rs9349379 and LMOD1 rs2820315 genotypes and alleles in patients with unstable angina and controls.

\begin{tabular}{|c|c|c|c|c|c|c|c|c|}
\hline & \multicolumn{2}{|c|}{ Control Group } & \multicolumn{2}{|c|}{ Unstable Angina } & \multirow{2}{*}{$p$ Value } & \multirow{2}{*}{$\begin{array}{c}\text { Compared Genotypes } \\
\text { or Alleles }\end{array}$} & \multirow{2}{*}{$p$ Value } & \multirow{2}{*}{ OR $(95 \% \mathrm{CI})$} \\
\hline & $\mathrm{n}$ & $\%$ & $\mathrm{n}$ & $\%$ & & & & \\
\hline \multicolumn{9}{|c|}{$\begin{array}{c}\text { PHACTR1 rs9349379 } \\
\text { genotype }\end{array}$} \\
\hline $\mathrm{AA}$ & 56 & $38.89 \%$ & 63 & $27.16 \%$ & \multirow{5}{*}{0.041} & GG+AG vs. AA & 0.017 & $1.71(1.10-2.66)$ \\
\hline AG & 70 & $48.61 \%$ & 126 & $54.31 \%$ & & GG vs. AG+AA & 0.12 & $1.59(0.88-2.89)$ \\
\hline \multirow{3}{*}{ GG } & 18 & $12.50 \%$ & 43 & $18.53 \%$ & & GG vs. AA & 0.024 & $2.12(1.10-4.10)$ \\
\hline & & & & & & AG vs. AA & 0.046 & $1.60(1.01-2.54)$ \\
\hline & & & & & & GG vs. AG & 0.37 & $1.33(0.71-2.47)$ \\
\hline \multicolumn{9}{|c|}{ Allele } \\
\hline A & 182 & $63.19 \%$ & 252 & $54.31 \%$ & & \multirow{2}{*}{ G vs. A } & \multirow{2}{*}{0.017} & \multirow{2}{*}{$1.44(1.07-1.95)$} \\
\hline G & 106 & $36.81 \%$ & 212 & $45.69 \%$ & & & & \\
\hline \multicolumn{9}{|c|}{$\begin{array}{l}\text { LMOD1 rs2820315 } \\
\text { genotype }\end{array}$} \\
\hline $\mathrm{CC}$ & 80 & $55.56 \%$ & 100 & $43.10 \%$ & \multirow{5}{*}{0.018} & $\mathrm{TT}+\mathrm{CT}$ vs. $\mathrm{CC}$ & 0.019 & $1.65(1.09-2.51)$ \\
\hline $\mathrm{CT}$ & 57 & $39.58 \%$ & 105 & $45.26 \%$ & & TT vs. CT+CC & 0.026 & $2.58(1.09-6.09)$ \\
\hline \multirow{3}{*}{ TT } & 7 & $4.86 \%$ & 27 & $11.64 \%$ & & TT vs. CC & 0.0094 & $3.09(1.28-7.45)$ \\
\hline & & & & & & CT vs. CC & 0.081 & $1.47(0.95-2.28)$ \\
\hline & & & & & & TT vs. CT & 0.10 & $2.09(0.86-5.11)$ \\
\hline \multicolumn{9}{|c|}{ Allele } \\
\hline C & 217 & $75.35 \%$ & 305 & $65.73 \%$ & & \multirow{2}{*}{ T vs. C } & \multirow{2}{*}{0.0054} & \multirow{2}{*}{$1.59(1.15-2.22)$} \\
\hline $\mathrm{T}$ & 71 & $24.65 \%$ & 159 & $34.27 \%$ & & & & \\
\hline
\end{tabular}


To examine whether the PHACTR1 rs9349379 G allele and LMOD1 rs2820315 T allele are independent factors predisposing to unstable angina, multivariate regression analysis was performed including: age, male sex, BMI, tobacco smoking, hypertension, diabetes, HDL serum level, and the number of PHACTR1 rs9349379 G and LMOD1 rs2820315 T alleles. In this analysis, the higher number of PHACTR1 rs9349379 G and LMOD1 rs2820315 T alleles, as well as age, male sex, hypertension, higher BMI, diabetes and low HDL serum level, were independent factors predisposing to unstable angina (Table 4).

In addition, we examined the associations between the studied polymorphisms and clinical factors predisposing to unstable angina (age, BMI, waist circumference, serum levels of total cholesterol, HDL cholesterol, LDL cholesterol and triacylglycerols). These associations were not statistically significant (Kruskal-Wallis test) except for the association between PHACTR1 rs9349379 genotype and HDL cholesterol level (Table 5).

Table 4. Multivariate logistic regression analysis using unstable angina as the dependent variable.

\begin{tabular}{ccc}
\hline Parameter & OR $\mathbf{( 9 5 \% ~ C I )}$ & $p$ Value \\
\hline Age (years) & $0.96(0.93-0.99)$ & 0.022 \\
Sex (male vs. female) & $4.60(2.25-9.39)$ & 0.000026 \\
BMI (kg/m $\left.{ }^{2}\right)$ & $1.20(1.09-1.32)$ & 0.00014 \\
Smoking & $2.06(0.94-4.49)$ & 0.069 \\
Arterial hypertension & $2.16(1.07-4.39)$ & 0.032 \\
Diabetes mellitus & $5.47(1.89-15.82)$ & 0.0016 \\
HDL (mg/dL) & $0.88(0.84-0.92)$ & $<0.00001$ \\
PHACTR1 rs9349379 (number of G alleles) & $1.70(1.04-2.79)$ & 0.034 \\
LMOD1 rs2820315 (number of T alleles) & $1.99(1.18-3.37)$ & 0.0098 \\
\hline
\end{tabular}

Table 5. Clinical features of patients with unstable angina stratified according to PHACTR1 rs9349379 genotypes.

\begin{tabular}{|c|c|c|c|c|c|c|c|c|c|c|c|c|c|c|}
\hline \multirow{3}{*}{ Parameters } & \multicolumn{10}{|c|}{ PHACTR1 rs9349379 Genotype } & \multirow{3}{*}{$p^{\#}$} & \multirow{3}{*}{$\begin{array}{l}\text { AA vs. } \\
\text { AG+GG }\end{array}$} & \multirow{3}{*}{$\begin{array}{c}\text { AA+AG } \\
\text { vs. GG } \\
p^{\&}\end{array}$} & \multirow{3}{*}{$\begin{array}{c}\text { AA vs. } \\
\text { GG }\end{array}$} \\
\hline & \multicolumn{3}{|c|}{ AA } & \multicolumn{2}{|l|}{ AG } & \multicolumn{2}{|l|}{ GG } & \multicolumn{2}{|l|}{$\mathbf{A A}+\mathbf{A G}$} & $\mathrm{AG}+\mathrm{GG}$ & & & & \\
\hline & $\mathbf{n}$ & Mean \pm SD & n & Mean \pm SD & n & Mean \pm SD & n & Mean \pm SD & $\mathbf{n}$ & Mean \pm SD & & & & \\
\hline Age (years) & 63 & $62.6 \pm 9.9$ & 126 & $61.4 \pm 8.9$ & 43 & $63.1 \pm 11.4$ & 189 & $61.8 \pm 9.2$ & 169 & $61.9 \pm 9.6$ & 0.54 & 0.62 & 0.42 & 0.74 \\
\hline BMI $\left(\mathrm{kg} / \mathrm{m}^{2}\right)$ & 63 & $27.9 \pm 3.7$ & 126 & $28.4 \pm 4.0$ & 43 & $28.9 \pm 4.1$ & 189 & $28.3 \pm 3.9$ & 169 & $28.5 \pm 4.0$ & 0.58 & 0.41 & 0.40 & 0.29 \\
\hline Waist (cm) & 63 & $93.0 \pm 10.0$ & 126 & $96.0 \pm 10.7$ & 43 & $95.3 \pm 10.0$ & 189 & $95.0 \pm 10.5$ & 169 & $95.8 \pm 10.5$ & 0.27 & 0.15 & 0.79 & 0.54 \\
\hline $\mathrm{CH}(\mathrm{mg} / \mathrm{dL})$ & 61 & $234.2 \pm 54.0$ & 120 & $225.9 \pm 55.1$ & 42 & $237.0 \pm 62.5$ & 181 & $228.7 \pm 54.7$ & 162 & $228.8 \pm 57.1$ & 0.33 & 0.32 & 0.45 & 0.95 \\
\hline $\operatorname{HDL}(\mathrm{mg} / \mathrm{dL})$ & 50 & $44.3 \pm 9.5$ & 103 & $43.9 \pm 8.1$ & 33 & $48.4 \pm 6.8$ & 153 & $44.0 \pm 8.5$ & 136 & $45.0 \pm 8.0$ & 0.01 & 0.34 & 0.002 & 0.01 \\
\hline LDL (mg/dL) & 50 & $168.9 \pm 47.9$ & 103 & $159.7 \pm 50.8$ & 33 & $168.4 \pm 53.8$ & 153 & $162.7 \pm 49.9$ & 136 & $161.8 \pm 51.5$ & 0.34 & 0.24 & 0.61 & 0.74 \\
\hline $\mathrm{TG}(\mathrm{mg} / \mathrm{dL})$ & 61 & $139.7 \pm 80.6$ & 119 & $138.2 \pm 74.2$ & 42 & $144.3 \pm 59.7$ & 180 & $138.7 \pm 76.2$ & 161 & $139.8 \pm 70.6$ & 0.58 & 0.63 & 0.30 & 0.31 \\
\hline
\end{tabular}

\#_Kruskal-Wallis test; \&_Mann-Whitney U test; BMI-body mass index, CH-total cholesterol in serum, HDL—high density cholesterol in serum; LDL-low density cholesterol in serum, TG—triacylglycerols in serum.

\section{Discussion}

The aim of this case-control association study was to evaluate the associations between the occurrence of acute coronary syndromes in the form of unstable angina and SNPs within the PECAM1, COL4A2, PHACTR1 and LMOD1 genes. These genes influence endothelial and vascular smooth muscle function and thus the development of the atherosclerotic process and the stability of the atherosclerotic plaque. The polymorphisms studied affect the expression of these genes and therefore may influence the atherosclerotic process and coronary artery disease. There were no significant differences in the distribution of PECAM1 rs1867624 and COL4A2 rs4773144 polymorphisms between patients with unstable angina and controls, suggesting that these polymorphisms do not increase the risk of unstable angina. In contrast, we found a statistically significant higher prevalence of the PHACTR1 rs9349379 G allele and the LMOD1 rs2820315 T allele in the group of patients with unstable angina. The association between these alleles and unstable angina was confirmed by multivariate logistic regression analysis, in which the number of the $G$ (PHACTR1 rs9349379) and T (LMOD1 rs2820315) alleles was an independent risk factor 
for unstable angina. The results suggest an association between PHACTR1 rs9349379 and LMOD1 rs2820315 polymorphisms and the risk of unstable angina.

The gene encoding phosphatase and actin regulator 1, PHACTR1, is located on chromosomal locus 6p24. The rs9349379 polymorphism is located within an intron of the PHACTR1 gene and is thought to be a regulatory region responsible for gene expression (eQTL-expression quantitative trait locus) in vascular tissue.

The present study demonstrates an association between the $G$ allele and the risk of unstable angina. These results are consistent with previous studies that suggest an association of the $\mathrm{G}$ allele of rs9349379 with the development of ischaemic heart disease and the occurrence of myocardial infarction [7].

Beaudoin et al. showed that SNP rs9349379 is correlated with a defect in the binding site for the MEF2 (myocyte enhancer factor 2) family of transcription factors, which play a key role in maintaining the integrity of the vascular bed [8]. MEF2 is responsible for transmitting extracellular signals to the genome and activating pathways that control cell differentiation, morphogenesis, proliferation and apoptosis. It also mediates epigenetic regulatory mechanisms involving changes in chromatin configurations and microRNA modulation [9]. However, there are no consistent data to date showing a direct association between MEF2 expression and the development of CAD. In contrast, the different binding of the $\mathrm{A}$ and $\mathrm{G}$ alleles to MEF2 results in altered PHACTR1 expression.

The $\mathrm{G}$ allele-associated defect in the binding site for MEF2 leads to decreased PHACTR1 expression in the coronary artery endothelium [8]. The product of PHACTR1 is protein phosphatase 1 (PP1) and actin binding protein. As a regulator of PP1 activity, it is highly expressed in the endothelium of the brain, heart and vasculature, playing an important role in tubulogenesis and endothelial apoptosis [10]. Among others, PP1 has a function in regulating endothelial NO production [11].

There are data showing an association between SNP rs9349379 and the development of coronary artery stenosis and calcification and early MI [12-14]. Pérez-Hernández et al. evaluated the effect of polymorphisms in the PHACTR1 gene (rs2026458 and rs9349379) on the risk of early CAD development in a Mexican population. Analysis after adjustment for age, sex, presence of hypertension, type 2 diabetes, dyslipidaemia and nicotinism suggested an association between the rs9349379 G allele and an increased likelihood of CAD at a younger age [15]. Hager et al. evaluated the effect of SNP rs9349379 on the incidence of CAD in a Lebanese population. Their analysis showed an association between the rs $9349379 \mathrm{G}$ allele and the degree of coronary stenosis [14]. Consistent with these observations are the results of a study conducted in a Chinese population, where a reduced incidence of CAD was found among individuals with the A allele [16]. Gupta et al. observed an increase in endothelin- 1 expression in the endothelium associated with the G allel [17]. This hormone is a potent endothelium-produced factor that causes vasoconstriction. Ford et al. also confirmed a positive correlation between the presence of the $\mathrm{G}$ allele and plasma endothelin-1 levels. They observed a higher prevalence of angina for this background associated with coronary microvascular dysfunction (CMD) in subjects without significant epicardial artery stenosis [18]. Kasikara et al. suggested that PHACTR1 deficiency may exacerbate atherosclerotic progression. The authors demonstrated that decreased PHACTR1 expression impairs the process of elimination of apoptotic remnants of dead macrophages called efferocytosis [19]. Efficient efferocytosis inhibits the inflammatory reaction and prevents secondary necrosis within the atherosclerotic plaque $[19,20]$. Reduced PHACTR1 expression in macrophages reduces the phosphorylation of myosin light chains, which are essential for phagocytosis of apoptotic remnants. Consequently, there is a significant reduction in efferocytosis, which promotes the formation of rupture-prone necrotic atherosclerotic plaques [21].

LMOD1 (leiomodin 1) belongs to the actin filament nucleator family and is found in smooth muscle cells, including VSMC. The gene encoding the protein is located at locus 1q32. LMOD2 and LMOD3 are not expressed in smooth muscle but are found in cardiac and skeletal muscle tissues [22]. Leiomodins are proteins that regulate actin filament function. 
They appear to play a significant role in maintaining the contractile function of striated and smooth muscle, and loss of these proteins significantly compromises the integrity of muscle tissue [23]. The current study found a significant increase in the risk of unstable angina in carriers of the LMOD1 rs2820315 T allele. These observations are consistent with the results of GWAS analyses, which suggest that the rs 2820315 polymorphism is significantly involved in the development of atherosclerotic lesions in coronary arteries [24]. The presence of the $\mathrm{T}$ allele is associated with reduced expression of LMOD1 and leads to a defect in the transcription factor FOXO3 (forkhead box O3) binding site [25]. As a result, there is a decrease in its transcriptional activity and consequently a decrease in $L M O D 1$ concentrations. The rs2820315 T allele results in decreased expression of LMOD1 in human coronary artery smooth muscle cells (HCASMC). Decreased expression leads to increased proliferation and migration and loss of contractile elements of VSMC. LMOD1 activity is also decreased by oxLDL particles, PDGF-BB and some cytokines (INF- $\gamma$ ) $[25,26]$.

Levula et al. evaluated gene expression in plaque fragments collected from femoral, carotid or abdominal aortic arteries. LMOD1 expression was 6.5-fold lower compared with control samples from internal mammary arteries [27]. LMOD1 appears to play a key role in maintaining the phenotype of differentiated VSMC and sustaining their contractile function. Its deficiency causes a loss of contractile elements and enhances VSMC differentiation into less mature cells with an embryonic stage-like phenotype. Epigenetic reprogramming of VSMC to a form exhibiting a high proliferation rate and invasiveness plays a key role in atherogenesis $[28,29]$. Studies on animal models convincingly demonstrate that up to more than $80 \%$ of all cells found in advanced atherosclerotic plaques are derived from VSMC. Phenotypically transformed muscle cells produce excess extracellular matrix, undergo apoptosis, accumulate lipids, secrete growth factors and proinflammatory cytokines, and contribute to monocyte recruitment [28].

PECAM1 (CD31) encodes platelet-endothelial cell adhesion factor 1, a trans-membrane glycoprotein belonging to the immunoglobulin family found on the surface of platelets, monocytes and neutrophils. The PECAM1 gene is located in the 17q23 region. PECAM-1 molecules interact with each other and bind to other molecules (cell-surface glycosaminoglycans, integrin $\alpha v \beta 3$, CD38, TCD31L) [29,30].

Studies on the effect of polymorphisms in the PECAM1 region on the risk of CAD and MI do not provide conclusive results [24]. The rs1867624 C allele is thought to be associated with higher PECAM1 expression and lower CAD risk. PECAM1 molecules are concentrated on the lateral surfaces of cell membranes. Mutual binding of PECAM1 molecules to each other through so-called trans-homophilic junctions leads to the formation of a specific protective barrier of the endothelium. Downregulation of their expression leads to a violation of the integrity of the endothelial barrier and an increase in its permeability, which consequently leads to the activation of inflammatory processes in the inner membrane of the artery [31,32]. Previous studies suggested a dual function of PECAM1 in the process of coronary arteriosclerosis. PECAM1 enhances the signal transduction required for proinflammatory expression of adhesion molecules at sites prone to atherosclerotic lesion development and may inhibit inflammatory responses by inhibiting NF- $\mathrm{KB}$ expression, revealing its anti-atherosclerotic potential [33].

The COL4A1/COL4A2 gene, which encodes type IV collagen, is located in the $13 q 34$ region and includes exons 52 and 48. This type of collagen is a major building block of the basement membrane, anchoring, via integrins and other surface molecules, the epithelial cell layer of most tissues and the vascular endothelium. Collagen fibres, also type IV, are furthermore found in the endothelial membrane of arteries, surrounding densely packed VSMC. COL4A1 encodes the $\alpha 1$ subunit. COL $4 A 2$ encodes the $\alpha 2$ subunit, which is one of the six subunits of type IV collagen [34,35]. COL4A1 and COL4A2 genes are separated by a common bidirectional promoter. Expression of both genes is controlled by TGF $\beta$, and a mediator necessary for this process is the SMAD3 protein. Studies indicate that transcription of $C O L 4 A 1$ and $C O L 4 A 2$ is modulated by non-coding regulatory intron sequences of these genes $[34,35]$. The SNP rs4773144 evaluated in this study is located 
within intron 3 of COL4A2 [36]. GWAS studies suggest the involvement of rs4773144 COL4A2 gene variants in the development of CAD and coronary artery calcification and increased risk of MI [12,37]. The results of the current study showed no association between the rs4773144 polymorphism and unstable angina.

In this study, we investigated genetic polymorphisms associated with an increased risk of coronary artery disease. To date, these polymorphisms were studied in various forms of coronary artery disease; however, the results are inconsistent. The results of our study suggest an association between PHACTR1 rs9349379 and LMOD1 rs2820315 polymorphisms and unstable angina. These genes affect endothelial and vascular smooth muscle function. It is likely that changes in the expression of these genes resulting from genetic polymorphisms may affect atherosclerotic plaque formation and stability and thus the risk of unstable angina. To date, several genetic polymorphisms that increase the risk of developing ischemic heart disease, including unstable angina, have been identified. It seems that genetic polymorphisms, together with well-known environmental risk factors, may be taken into account as factors influencing the occurrence of unstable angina.

\section{Conclusions}

The results of this study suggest that PHACTR1 rs9349379 and LMOD1 rs2820315 gene polymorphisms are associated with an increased risk of unstable angina. The presence of PHACTR1 rs9349379 G and LMOD1 rs2820315 T alleles is a risk factor for unstable angina. No statistically significant association was found between PECAM1 rs1867624 and COL4A2 rs4773144 gene polymorphisms and the risk of unstable angina.

Author Contributions: K.K., investigation, interpretation of data for the work; D.M., genetic analysis; K.S., statistical analysis, interpretation of data for the work; V.D., formal analysis, manuscript preparation; A.P., conceptualization and manuscript preparation. All authors have read and agreed to the published version of the manuscript.

Funding: The project is financed from the program of the Minister of Science and Higher Educationunder the name "Regional Initiative of Excellence" in 2019-2022 project number 002/RID/2018-19.

Institutional Review Board Statement: The study was approved by the Ethics Committee of Pomeranian Medical University, Szczecin, Poland (KB-0012/46/17).

Informed Consent Statement: Informed consent was obtained from all subjects involved in the study.

Data Availability Statement: Not applicable.

Conflicts of Interest: The authors declare no conflict of interest.

\section{References}

1. McPherson, R.; Tybjaerg-Hansen, A. Genetics of Coronary Artery Disease. Circ. Res. 2016, 118, 564-578. [CrossRef]

2. Hansson, G.K. Inflammation, atherosclerosis, and coronary artery disease. N. Engl. J. Med. 2005, 352, 168516-168595. [CrossRef] [PubMed]

3. Eble, J.A.; Niland, S. The Extracellular Matrix of Blood Vessels. Curr. Pharm. Des. 2009, 15, 1385-1400. [CrossRef] [PubMed]

4. Gimbrone, M.A., Jr.; García-Cardeña, G. Endothelial Cell Dysfunction and the Pathobiology of Atherosclerosis. Circ. Res. 2016, 118, 620-636. [CrossRef]

5. Davies, P.F. Hemodynamic shear stress and the endothelium in cardiovascular pathophysiology. Nat. Clin. Pract. Cardiovasc. Med. 2009, 6, 16-26. [CrossRef] [PubMed]

6. Steffel, J.; Lüscher, T.F.; Tanner, F.C. Tissue factor in cardiovascular diseases: Molecular mechanisms and clinical implications. Circulation 2006, 113, 722-731. [CrossRef]

7. Wang, X.; Musunuru, K. Confirmation of Causal rs9349379- PHACTR1 Expression Quantitative Trait Locus in Human-Induced Pluripotent Stem Cell Endothelial Cells. Circ. Genom. Precis. Med. 2018, 11, e002327. [CrossRef]

8. $\quad$ Beaudoin, M.; Gupta, R.M.; Won, H.H.; Lo, K.S.; Do, R.; Henderson, C.A.; Lavoie-St-Amour, C.; Langlois, S.; Rivas, D.; Lehoux, S.; et al. Myocardial Infarction-Associated SNP at 6p24 Interferes With MEF2 Binding and Associates with PHACTR1 Expression Levels in Human Coronary Arteries. Arterioscler. Thromb. Vasc. Biol. 2015, 35, 1472-1479. [CrossRef]

9. Potthoff, M.J.; Olson, E.N. MEF2: A central regulator of diverse developmental programs. Development 2007, 134, 4131-4140. [CrossRef] 
10. Jarray, R.; Allain, B.; Borriello, L.; Biard, D.; Loukaci, A.; Larghero, J.; Hadj-Slimane, R.; Garbay, C.; Lepelletier, Y.; Raynaud, F. Depletion of the novel protein PHACTR-1 from human endothelial cells abolishes tube formation and induces cell death receptor apoptosis. Biochimie 2011, 93, 1668-1675. [CrossRef]

11. Mount, P.F.; Kemp, B.E.; Power, D.A. Regulation of endothelial and myocardial NO synthesis by multi-site eNOS phosphorylation. J. Mol. Cell Cardiol. 2007, 42, 271-279. [CrossRef]

12. O’Donnell, C.J.; Kavousi, M.; Smith, A.V.; Kardia, S.L.; Feitosa, M.F.; Hwang, S.J.; Sun, Y.V.; Province, M.A.; Aspelund, T.; Dehghan, A.; et al. Genome-wide association study for coronary artery calcification with follow-up in myocardial infarction. Circulation 2011, 124, 2855-2864. [CrossRef]

13. Myocardial Infarction Genetics Consortium; Kathiresan, S.; Voight, B.F.; Purcell, S.; Musunuru, K.; Ardissino, D.; Mannucci, P.M.; Anand, S.; Engert, J.C.; Samani, N.J.; et al. Genome-wide association of early-onset myocardial infarction with single nucleotide polymorphisms and copy number variants. Nat. Genet. 2009, 41, 334-341. [CrossRef]

14. Hager, J.; Kamatani, Y.; Cazier, J.B.; Youhanna, S.; Ghassibe-Sabbagh, M.; Platt, D.E.; Abchee, A.B.; Romanos, J.; Khazen, G.; Othman, R.; et al. Genome-wide association study in a Lebanese cohort confirms PHACTR1 as a major determinant of coronary artery stenosis. PLoS ONE 2012, 7, e38663. [CrossRef]

15. Pérez-Hernández, N.; Vargas-Alarcón, G.; Posadas-Sánchez, R.; Martínez-Rodríguez, N.; Tovilla-Zárate, C.A.; Rodríguez-Cortés, A.A.; Pérez-Méndez, O.; Blachman-Braun, R.; Rodríguez-Pérez, J.M. PHACTR1 Gene Polymorphism Is Associated with Increased Risk of Developing Premature Coronary Artery Disease in Mexican Population. Int. J. Environ. Res. Public Health 2016, 13, 803. [CrossRef] [PubMed]

16. Chen, L.; Qian, H.; Luo, Z.; Li, D.; Xu, H.; Chen, J.; He, P.; Zhou, X.; Zhang, T.; Chen, J.; et al. PHACTR1 gene polymorphism with the risk of coronary artery disease in Chinese Han population. Postgrad. Med. J. 2019, 95, 67-71. [CrossRef]

17. Gupta, R.M.; Hadaya, J.; Trehan, A.; Zekavat, S.M.; Roselli, C.; Klarin, D.; Emdin, C.A.; Hilvering, C.R.E.; Bianchi, V.; Mueller, C.; et al. A Genetic Variant Associated with Five Vascular Diseases Is a Distal Regulator of Endothelin-1 Gene Expression. Cell 2017, 170, 522-533.e15. [CrossRef] [PubMed]

18. Ford, T.J.; Corcoran, D.; Padmanabhan, S.; Aman, A.; Rocchiccioli, P.; Good, R.; McEntegart, M.; Maguire, J.J.; Watkins, S.; Eteiba, H.; et al. Genetic dysregulation of endothelin-1 is implicated in coronary microvascular dysfunction. Eur. Heart J. 2020, 41, 3239-3252. [CrossRef]

19. Kasikara, C.; Schilperoort, M.; Gerlach, B.; Xue, C.; Wang, X.; Zheng, Z.; Kuriakose, G.; Dorweiler, B.; Zhang, H.; Fredman, G.; et al. Deficiency of macrophage PHACTR1 impairs efferocytosis and promotes atherosclerotic plaque necrosis. J. Clin. Investig. 2021, 131, e145275. [CrossRef]

20. Brophy, M.L.; Dong, Y.; Wu, H.; Rahman, H.N.; Song, K.; Chen, H. Eating the Dead to Keep Atherosclerosis at Bay. Front. Cardiovasc. Med. 2017, 4, 2. [CrossRef] [PubMed]

21. Clarke, M.C.; Talib, S.; Figg, N.L.; Bennett, M.R. Vascular smooth muscle cell apoptosis induces interleukin-1-directed inflammation: Effects of hyperlipidemia-mediated inhibition of phagocytosis. Circ. Res. 2010, 106, 363-372. [CrossRef]

22. Nworu, C.U.; Kraft, R.; Schnurr, D.C.; Gregorio, C.C.; Krieg, P.A. Leiomodin 3 and tropomodulin 4 have overlapping functions during skeletal myofibrillogenesis. J. Cell Sci. 2015, 128, 239-250. [CrossRef]

23. Tolkatchev, D.; Gregorio, C.C.; Kostyukova, A.S. The role of leiomodin in actin dynamics: A new road or a secret gate. FEBS J. 2021, in press. [CrossRef] [PubMed]

24. Howson, J.M.M.; Zhao, W.; Barnes, D.R.; Ho, W.K.; Young, R.; Paul, D.S.; Waite, L.L.; Freitag, D.F.; Fauman, E.B.; Salfati, E.L.; et al. Fifteen new risk loci for coronary artery disease highlight arterial-wall-specific mechanisms. Nat. Genet. 2017, 49, 1113-1119. [CrossRef] [PubMed]

25. Nanda, V.; Wang, T.; Pjanic, M.; Liu, B.; Nguyen, T.; Matic, L.P.; Hedin, U.; Koplev, S.; Ma, L.; Franzén, O.; et al. Functional regulatory mechanism of smooth muscle cell-restricted LMOD1 coronary artery disease locus. PLoS Genet. 2018, 14, e1007755. [CrossRef]

26. Perisic Matic, L.; Rykaczewska, U.; Razuvaev, A.; Sabater-Lleal, M.; Lengquist, M.; Miller, C.L.; Ericsson, I.; Röhl, S.; Kronqvist, M.; Aldi, S.; et al. Phenotypic Modulation of Smooth Muscle Cells in Atherosclerosis Is Associated With Downregulation of LMOD1, SYNPO2, PDLIM7, PLN, and SYNM. Arterioscler. Thromb. Vasc. Biol. 2016, 36, 1947-1961. [CrossRef] [PubMed]

27. Levula, M.; Oksala, N.; Airla, N.; Zeitlin, R.; Salenius, J.P.; Järvinen, O.; Venermo, M.; Partio, T.; Saarinen, J.; Somppi, T.; et al. Genes involved in systemic and arterial bed dependent atherosclerosis-Tampere Vascular study. PLoS ONE 2012, 7, e33787. [CrossRef] [PubMed]

28. Miller, C.L.; Pjanic, M.; Wang, T.; Nguyen, T.; Cohain, A.; Lee, J.D.; Perisic, L.; Hedin, U.; Kundu, R.K.; Majmudar, D.; et al. Integrative functional genomics identifies regulatory mechanisms at coronary artery disease loci. Nat. Commun. 2016, 7, 12092. [CrossRef]

29. Wong, D.; Turner, A.W.; Miller, C.L. Genetic Insights into Smooth Muscle Cell Contributions to Coronary Artery Disease. Arterioscler. Thromb. Vasc Biol. 2019, 39, 1006-1017. [CrossRef]

30. Caligiuri, G. CD31 as a Therapeutic Target in Atherosclerosis. Circ. Res. 2020, 126, 1178-1189. [CrossRef]

31. Privratsky, J.; Paddock, C.M.; Florey, O.; Newman, D.K.; Muller, W.A.; Newman, P.J. Relative contribution of PECAM-1 adhesion and signaling to the maintenance of vascular integrity. J. Cell Sci. 2011, 124 Pt 9, 1477-1485. [CrossRef]

32. Ren, Q.; Ren, L.; Ren, C.; Liu, X.; Dong, C.; Zhang, X. Platelet endothelial cell adhesion molecule-1 (PECAM1) plays a critical role in the maintenance of human vascular endothelial barrier function. Cell Biochem. Funct. 2015, 33, 560-565. [CrossRef] 
33. Goel, R.; Schrank, B.R.; Arora, S.; Boylan, B.; Fleming, B.; Miura, H.; Newman, P.J.; Molthen, R.C.; Newman, D.K. Site-specific effects of PECAM-1 on atherosclerosis in LDL receptor-deficient mice. Arterioscler. Thromb. Vasc. Biol. 2008, 28, 1996-2002. [CrossRef] [PubMed]

34. Caligiuri, G. Mechanotransduction, immunoregulation, and metabolic functions of CD31 in cardiovascular pathophysiology. Cardiovasc. Res. 2019, 115, 1425-1434. [CrossRef]

35. Turner, A.W.; Nikpay, M.; Silva, A.; Lau, P.; Martinuk, A.; Linseman, T.A.; Soubeyrand, S.; McPherson, R. Functional interaction between COL4A1/COL4A2 and SMAD3 risk loci for coronary artery disease. Atherosclerosis 2015, 242, 543-552. [CrossRef] [PubMed]

36. Yang, W.; Ng, F.L.; Chan, K.; Pu, X.; Poston, R.N.; Ren, M.; An, W.; Zhang, R.; Wu, J.; Yan, S.; et al. Coronary-Heart-DiseaseAssociated Genetic Variant at the COL4A1/COL4A2 Locus Affects COL4A1/COL4A2 Expression, Vascular Cell Survival, Atherosclerotic Plaque Stability and Risk of Myocardial Infarction. PLoS Genet. 2016, 12, e1006127. [CrossRef] [PubMed]

37. Schunkert, H.; König, I.R.; Kathiresan, S.; Reilly, M.P.; Assimes, T.L.; Holm, H.; Preuss, M.; Stewart, A.F.; Barbalic, M.; Gieger, C.; et al. Large-scale association analysis identifies 13 new susceptibility loci for coronary artery disease. Nat. Genet. 2011, 43, 333-338. [CrossRef] [PubMed] 